\title{
PRENATAL ULTRASOUND SCREENING TO DIAGNOSE CONGENITAL ANOMALIES AMONG ONE THOUSAND UNSELECTED WOMEN AND THEIR PREGNANCY OUTCOME
}

Jhuma Biswas, Kaushik De, Shyamal Dasgupta, Biswajit Ghosh, Poushali Sanyal, Amitava Mukherjee

1. Assistant Professor. Department of Obstetrics \& Gynaecology, IPGME\&R, Kolkata, India.

2. Medical Officer. Department of Radiology, Domkal Sub divisional Hospital, West Bengal, India

3. Assistant Professor. Department of Obstetrics \& Gynaecology, IPGME\&R, Kolkata, India.

4. Assistant Professor. Department of Obstetrics \& Gynaecology, IPGME\&R, Kolkata, India.

5. Clinical Tutor. Department of Obstetrics \& Gynaecology, IPGME\&R, Kolkata, India.

6. Professor. Department of Obstetrics \& Gynaecology, Maldah Medical College and Hospital, West Bengal, India.

\section{CORRESPONDING AUTHOR:}

Jhuma Biswas, 15P, Roypur Mondal Para Road, Ganguli Bagan, Kolkata-700047,

West Bengal, India.

E-mail: drjhumabiswas@yahoo.in

ABSTRACT: OBJECTIVES: Purpose of our study was to determine the detection rate of congenital anomalies in second trimester by single prenatal ultrasound screening in an unselected population and to evaluate the subsequent pregnancy outcome and to compare the results with published series using standardized criteria. SUBJECTS AND METHODS- One thousand pregnant women at 18-22 weeks' gestation were screened by prenatal ultrasound examination. We compared these sonographic reports with pregnancy outcomes established by postnatal echocardiography and ultrasound examinations of neonates and autopsy for dead fetuses. Statistical analysis was performed on two units; malformed fetus and malformation itself. RESULTS- A total of 27 fetuses with 30 anomalies were identified by prenatal ultrasound. Prospectively 2 babies with 2 anomalies were found to be normal. On postnatal examination 13 babies were found to have 14 anomalies which could not be detected by ultrasound. Thus the sensitivity of ultrasound in detecting congenital anomalies and anomalous fetuses was $66.6 \%$ and $67.5 \%$ respectively. Highest detection rate was observed for CNS anomalies (88.8\%) but that of craniofacial and musculoskeletal anomalies was not very satisfactory (33\% in each system). CONCLUSION-This study shows rate of detection of fetal anomalies is satisfactory for most organ systems except cardiac, musculoskeletal and craniofacial malformations.

KEY WORDS: Prenatal Ultrasound, Ultrasound Screening, congenital anomaly, anomaly scan, pregnancy outcome.

INTRODUCTION: The term 'congenital anomaly' is used interchangeably with birth defects and malformation. Incidence of major abnormalities discovered at birth is 2-3 per thousand live births worldwide $[1,2]$. Despite their relatively low incidence, fetal malformations are responsible for $30 \%$ of perinatal deaths in addition to considerable infant morbidity in developed countries [3-5].Major malformations are lethal abnormalities or those that are incurable and liable to incur marked handicap or those requiring major surgical intervention [6].Up till the early 1970s, prenatal diagnosis of congenital anomalies was primarily aimed at 
detecting chromosomal abnormalities by amniocentesis [7]. At present, invasive prenatal diagnostic tests continue to be the gold standard for pregnancies at increased risk to have chromosomal anomaly or genetic disease. Still, invasive techniques are restricted to subgroups at risk for anomalies where such time consuming procedures are cost effective, also accounting for procedure related abortive risks. For low risk population among noninvasive screening tests prenatal ultrasonography is the most widely used and well accepted procedure to detect fetal congenital anomalies. Our study was an attempt to detect the incidence of congenital anomalies by a single pelvic ultrasound examination performed at 18-22 weeks of gestation in an unselected population of 1000 women, evaluate the pregnancy outcome, \& compare the results with published series using standardized criteria.

MATERIALS AND METHODS: Place of study: This was a prospective study conducted from September 2006 through August 2007 in the department of Obstetrics and Gynaecology, Vivekananda Institute Of Medical Sciences, West Bengal, India.

Study-population: Anomaly scan was performed among 1000 consecutive pregnant women between 18-22 weeks period of gestation.

Inclusion Criteria: Pregnant women between 18-22 weeks period of gestation, irrespective of age, parity or history of previous affected baby with congenital malformation.

Ultrasounds were performed by radiologists using Siemens and GE machine with 3.5 to $5 \mathrm{MHz}$ curvilinear probe.

Pregnancy outcome was divided into:

- Termination of Pregnancy (with oral mifepristone and vaginal misoprostol tablets); in all cases autopsy was performed to confirm the diagnosis.

- Intrauterine fetal death

- Live birth with major anomaly/anomalies

- Live birth with minor anomaly/anomalies

Follow up investigations were done, where necessary up to seventh postnatal day.

RESULT AND ANALYSIS: The statistical analysis was performed on two units: malformed fetus and malformation itself.

Table 01: detection rate of anomalous fetuses by 22 weeks' gestation

\begin{tabular}{|l|l|l|l|r|}
\hline $\begin{array}{l}\text { Number of of } \\
\text { pregnancies } \\
\text { screened }\end{array}$ & $\begin{array}{l}\text { Number } \\
\text { anomalous fetus in } \\
\text { population }\end{array}$ & $\begin{array}{l}\text { Number of anomalous } \\
\text { fetus diagnosed by } \\
\text { prenatal ultrasound }\end{array}$ & $\begin{array}{l}\text { Percentage } \\
\text { anomalous fetus } \\
\text { diagnosed prenatally }\end{array}$ \\
\hline 1000 & 38 & 25 & 65.8 & \\
\hline
\end{tabular}

Table 02: Detection rate of anomalies by 22 weeks' gestation

\begin{tabular}{|l|lr|l|lr|}
\hline $\begin{array}{l}\text { Number } \\
\text { pregnancies } \\
\text { screened }\end{array}$ & $\begin{array}{l}\text { of } \\
\text { anomalies } \\
\text { population }\end{array}$ & among & $\begin{array}{l}\text { Incidence of anomalies } \\
\text { by prenatal ultrasound }\end{array}$ & $\begin{array}{l}\text { Percentage } \\
\text { anomalies } \\
\text { prenatally }\end{array}$ & $\begin{array}{r}\text { of } \\
\text { diagnosed }\end{array}$ \\
\hline 1000 & 42 & 28 & 66.66 & \\
\hline
\end{tabular}

After birth 42 anomalies were detected in 38 babies, who had prenatal screening at 1822 weeks' gestation. By prenatal USG 30 anomalies among 27 fetuses were identified. Two anomalies suspected on USG were not present (suspected cleft lip and suspected VSD respectively), confirmed by 7 days postnatally. Therefore actually 28 anomalies were detected 
among 25 fetuses by prenatal ultrasound and postnatally 13 babies with 14 malformations were found whose anomalies were undetected by prenatal ultrasound.

Among 25 anomalous fetuses diagnosed prenatally 19 had major and 6 had minor anomalies. There was no false detection of any major anomaly. Eighteen fetuses were born with lethal malformations and among them one had Down's syndrome. Diagnosis of Down's syndrome was confirmed by amniocentesis done at 18 weeks' gestations. One case of cystic hygroma in occipital region was detected, pregnancy continued and no fetal demise happened.

Table 03: Detection rate of anomalies in different organ systems by prenatal ultrasound

\begin{tabular}{|l|l|l|l|}
\hline Organ system & $\begin{array}{l}\text { Number of anomalies } \\
\text { detected by ultrasound }\end{array}$ & $\begin{array}{l}\text { Number of anomalies in } \\
\text { screened population }\end{array}$ & $\begin{array}{l}\text { Percentage of } \\
\text { detection }\end{array}$ \\
\hline CNS & 8 & 9 & 88.88 \\
\hline Genitourinary & 6 & 7 & 85.71 \\
\hline Gastrointestinal & 5 & 7 & 71.43 \\
\hline Cardiovascular & 5 & 10 & 50.00 \\
\hline Musculoskeletal & 1 & 3 & 33.33 \\
\hline Craniofacial & 1 & 3 & 33.33 \\
\hline Others & 2 & 3 & 66.66 \\
\hline
\end{tabular}

Detection rate was highest for CNS anomalies (88.88\%) and lowest for craniofacial (33.33\%) and musculoskeletal (33.33\%) anomalies.

Table 04: Accuracy of ultrasound in detection of fetal malformations

\begin{tabular}{|l|l|l|}
\hline Result of USG screening & $\begin{array}{l}\text { Diagnosis } \\
\text { Anomaly present Anomaly absent }\end{array}$ & Total \\
\hline Positive & 2802 & 30 \\
\hline Negative & 14956 & 970 \\
\hline Total & 42958 & 1000 \\
\hline
\end{tabular}

DISCUSSION: Although 50-60\% of all structural abnormalities can be detected by ultrasound as early as 11-14 weeks' gestation, the optimum timing for full structural survey appears to be around 20 weeks of gestation[8].In comparing our results with prior studies, we standardized the definition of fetal anomaly by excluding all anomalies as given by European Congenital Anomaly Register[9].

Our results showed $99.7 \%$ specificity and $66.6 \%$ sensitivity in detection of congenital anomalies by prenatal ultrasound screening. Similarly studies conducted by Shirley et al[11] and Chitty et al [12] had a sensitivity of $67 \%$ and $74 \%$ respectively and a specificity of $99 \%$ in both. The accuracy in detecting congenital anomalies by ultrasound varies widely among centers and operators. Nonetheless, the overall sensitivity for ultrasonographically detectable fetal malformations was 35\% in tertiary health-care facilities which was significantly higher compared to $13 \%$ in community hospitals, suggesting that operator experience, skills and training are important determinants [13]. 
Table 05: Rate of termination of pregnancy (TOP) for fetal anomalies in published series

\begin{tabular}{|l|l|l|l|}
\hline Study name & Number of TOP & Number of anomalies detected & Percentage of TOP \\
\hline RADIUS trial [10] & 10 & 31 & 33.3 \\
\hline Chitty et al[12] & 52 & 93 & 55.9 \\
\hline Helsinki trial [14] & 11 & 18 & 61.1 \\
\hline Anderson et al[9] & 42 & 93 & 45.2 \\
\hline Present study & 16 & 28 & 57.14 \\
\hline
\end{tabular}

The detection of congenital anomaly at prenatal sonography was associated with a reduction in the rate of babies born with major malformation in our study and in most prior studies. In RADIUS trial there was no difference in the rate of adverse outcome in the screened population for anomalies detected compared to anomalies not detected perhaps due to low rate of termination of pregnancy.

ADVERSE PREGNANCY OUTCOME: Live birth with major anomaly is known as adverse pregnancy outcome as defined in the study by Anderson et al. Some authors discuss outcome in terms of neonatal intensive care admissions, cosmetic or surgical severity of the malformations.

Table 06: Summary of outcomes of fetal anomalies in published series

\begin{tabular}{|c|c|c|c|c|c|}
\hline Study name & \multicolumn{2}{|c|}{$\begin{array}{c}\text { Number of babies with } \\
\text { anomalies }\end{array}$} & \multicolumn{2}{c|}{ Adverse outcome including death } \\
\cline { 2 - 6 } & $\begin{array}{c}\text { Detected at } \\
\text { sonography }\end{array}$ & $\begin{array}{c}\text { Not detected at } \\
\text { sonography }\end{array}$ & $\begin{array}{c}\text { Anomalies } \\
\text { detected (\%) }\end{array}$ & $\begin{array}{c}\text { Anomalies not } \\
\text { detected (\%) }\end{array}$ & P value \\
\hline RADIUS[10] & 31 & 122 & $9(29)$ & $39(32)$ & $\begin{array}{c}\text { Not } \\
\text { significant }\end{array}$ \\
\hline $\begin{array}{c}\text { Anderson et } \\
\text { al[9] }\end{array}$ & 84 & 60 & $39(46)$ & $54(90)$ & $<0.001$ \\
\hline $\begin{array}{c}\text { Chitty et } \\
\text { al12] }\end{array}$ & 93 & 32 & $20(22)$ & $17(53)$ & $<0.01$ \\
\hline $\begin{array}{c}\text { Present } \\
\text { study }\end{array}$ & 25 & 13 & $3(12)$ & $6(46.2)$ & $<0.001$ \\
\hline
\end{tabular}

In present study only 2 out of 25 pregnancies with malformations, diagnosed prenatally were born with major malformation and one died in utero. So adverse outcome goes up to $12 \%$ when spontaneous death has been taken into consideration. There were 4 fetuses in the adverse outcome group whose anomalies remained undetected by prenatal ultrasound(30.8\%).Thus there were fewer babies born with major malformations in the group where anomalies were detected prenatally(12\%) than in the group where anomalies were undetected(46.2\%).A major impact of antenatal diagnosis of malformations is related to severity of the malformations detected. Most severe anomalies are reportedly detected earlier than minor ones, which especially relevant in many countries where only before viability is termination of pregnancy authorized by law. A recent meta analysis assessing the use of routine ultrasound compared to selective ultrasound before 24 weeks' gestation has shown that where detection of fetal abnormality was a specific aim of the examination, earlier detection of clinically unsuspected fetal malformation occurred. As a result, an increased rate of pregnancy termination was 
recorded in study groups undergoing prenatal ultrasound screening[15].The impact of the high pregnancy termination rate is a decrease in prevalence of live births affected with severe malformations, of the order of $20-30 \%[16-18]$.

CONCLUSION: We detected $66 \%$ of fetal anomalies in thousand screened population at 18-22 weeks of gestation. Our rate of detection for fetal anomalies was satisfactory for most of the organ systems except that for musculoskeletal, craniofacial and cardiac anomalies. Adverse pregnancy outcome was significantly lower in women where malformations could be detected by prenatal ultrasound due to higher rate of termination of pregnancies. Improvement in detection of craniofacial, musculoskeletal, and cardiac malformations remains a challenge for sonographers and radiologists and obstretricians.

\section{REFERENCES:}

1. Grandjean H,Larroque D, Levi S.Sensitivity of routine ultrasound screening of pregnancies in Eurofetus database. The Eurofetus Team. Ann N Y Acad Sci 1998; 847: 118-24.

2. Stoll C,Clementi M.Prenatal diagnosis of dysmorphic syndromes by routine fetal ultrasound examination across Europe. Ultrasound Obstet Gynecol 2003; 21(6):5435.

3. Marden PM, Smith DW, McDonald MJ. Congenital anomalies in the newborn infant, including minor variations. J Pediatr 1964; 64:357-371

4. Kalter H, Warkany J. Congenital malformations (first of two parts). N Engl J Med 1983;308:424-431

5. Kalter H, Warkany J. Congenital malformations (second of two parts). N Engl J Med 1983;308:491-497

6. Grandjean H,Larroque D, Levi $S$ et al. The performance of routine ultrasound screening of pregnancies in the Eurofetus study. Am J Obstet Gynecol 1999;181:446454.

7. Steele MW, Breg WR. Chromosome analysis of human amniotic fluid cells. Lancet 1966;1:383-385

8. Roberts N, Bhide A. Ultrasound prenatal diagnosis of structural abnormalities: Obstetrics, Gynecology \& Reproductive Medicine 2007;17:1-8.

9. Anderson N, Boswell O, Duff G. Prenatal sonography for the detection of fetal anomalies: a prospective study and comparison with prior series.AJR 1995;165:943950.

10. Ewigman BG, Crane JP, Frigoletto FD et al. Effects of prenatal ultrasound screening on perinatal outcome.RADIUS Study Group. N Engl J Med 1993;329:821-827.

11. Shirley IM, Bottomley F, Robinson VP. Routine radiographer screening for fetal abnormalities by ultrasound in an unselected low risk population. British J Rdiol 1992;65:564-569.

12. Chitty LS, Hung GH, Moore J et al. Effectiveness of routine sonography in detecting fetal structural abnormalities in low risk population.BMJ 1992;303:1165-1169.

13. Crane JP, LeFevre ML, Winborn RC, Evans JK, Ewingman BG, Bain RP, Frigoletto FD, McNellis D, RADIUS Study Group. A randomised trial of prenatal ultrasonographic screening: Impact on the detection, management, and outcome of anomalous fetuses. Am J Obstet Gynecol 1994;171:392-399 
14. Saad-Kamppainen A, Karjalainen O, Ylostalo P, Heinonen OR. Ultrasound screening and perinatal mortality: controlled trial of systematic one stage screening in pregnancy. The Helsinki Ultrasound Trial. Lancet 1990; 336:387-391.

15. Neilson JP. Ultrasound for fetal assessment in early pregnancy. The Cochrane Database of Systematic Reviews 2000;2

16. Boyd PA, Chamberlain P, Hicks NR. 6-year experience of prenatal diagnosis in an unselected population in Oxford, UK. Lancet 1998; 352:1577-1781

17. Zimmer EZ, Avraham Z, Sujoy P, Goldstein I, Bronshtein M. The influence of prenatal ultrasound on the prevalence of congenital anomalies at birth. Prenat Diagn 1997; 17:623-628

18. Bull C. Current and potential impact of fetal diagnosis on prevalence and spectrum of serious congenital heart disease at term in the UK. Lancet 1999; 354:1242-1247 